\title{
Environmental Fresh-cut Fruits or Vegetables Packages from Nonwoven Bagasse Fibers
}

\author{
Azza Mohamed Mohamed El Halwany ${ }^{1}$, Mohamed Hassan Hosny Aly ${ }^{2}$
}

1-Lecturer of Textile Department- Faculty of Applied Arts- Beni-Suef University

2- Bread and Pasta Department- Researcher at Food Technology Research Institute

\begin{tabular}{l|l|l|l} 
Submit Date: 2020-06-15 05:16:32 & Revise Date: 2021-01-01 13:25:55 & Accept Date: 2021-01-02 02:01:19
\end{tabular}

DOI: 10.21608 /jdsaa.2021.32753.1065

\section{Keywords:}

Bagasse Fibers-Waste Materials-

Natural Packages-Degradable-Fresh cut Fruits or Vegeta-

bles- Nonwoven Packages.

\begin{abstract}
:
Bagasse fiber is a waste product from sugar cane industry, which extracted from sugar-cane with approximately $30 \%$ cellulose content, and this fiber provides a natural source for nonwoven industries.

Even though untreated Bagasse fibers became more attention because of the increasing concern for disposal of agricultural residuals and the need for enhancing the sugar cane industry's profitability.

However, there are different methods to evaluate Bagasse fibers properties.

Using of Bagasse fibers as a food packing materials is a very important trend to improve our lifestyle. There are a lot of packing kinds which making from unhealthy materials like plastic packages.

Using Natural materials as a packing material is a global trend especially recycles waste fibers to make new products from these materials.

The high relative humidity $(\mathrm{RH})$ of packaged fresh-cut fruits or vegetables that is associated with spoilage due to the microbial growth.

Packing materials should protect the products against the microbial growth.

Potential antimicrobial compounds, as well as possible applications to preserve fresh-cut produce and future research in this area. The results show that using of packages made from Bagasse fibers , are more economic, and give more long life for the products which saving in them.

Use of waste materials like Bagasse is a good environmental solution that can be degradable naturally.
\end{abstract}




\section{Introduction}

In the last decade, because of increasing environmental awareness, natural fibers have attracted a great attention of the researchers due to the advantages with availability, low cost, low density, biodegradability, and other specific properties over traditional reinforcement fibers.

Waste generated from the plastics has been a pressing problem for many years because of their resistance to degradation.

The environmental impact caused by excessive quantity of non-degradable waste materials is necessitating research and efforts to develop new alternate materials that can be manufactured with the utilization of environmentally friendly raw materials, therefore, it is necessary to use this waste to convert into value-added products along with the utilization for the production of fuel, chemicals, papers, newspapers, etc.

Sugarcane bagasse is complex composite of cellulose (40-50\%), hemicelluloses (25-35\%), and lignin (15$35 \%$ ) with other impurities, and it is a good source of cellulose fiber which can be converted to natural food packaging material 8,4 .

Sugarcane is among the principal agricultural crops cultivated in tropical countries.

The annual world production of sugarcane is 1.6 billion tons, and it generates 279 million metric tons (MMT) of biomass residues (Bagasse and leaves). Sugarcane residues, particularly sugarcane Bagasse (SB) and leaves (SL) have been explored for both biotechnological and non biotechnological applications. For the last three decades, SB and SL have been explored for use in lignocelluloses bioconversion, which offers opportunities for the economic utilization of residual substrates in the production of Bagasse 3 .

\section{Background}

\subsection{Sugarcane Bagasse (SB)}

Bagasse is the fibrous residue which remains after sugarcane stalks are crushed to extract their juice. It is mainly used as a burning raw material in the sugar mill furnaces. The low caloric power of Bagasse makes this a low efficiency process.

Also, the sugarcane mill management encounters problems regarding regulations of clean air from the Environmental Protection Agency, due to the quality of the smoke released in the atmosphere 8, 2 .

Presently $85 \%$ of Bagasse production is burnt, the excess of Bagasse usually deposited on empty fields altering the landscape.

Approximately $9 \%$ of Bagasse is used in alcohol (ethanol) production. Ethanol is not just a good replacement for the fossil fuels, but it is also an environmentally friendly fuel.

Apart from this, ethanol is a very versatile chemical raw material from which a variety of chemicals can be produced 13 .

SB wastes are chosen as an ideal raw material in manufacturing new products because of its low fabricating costs and high quality green end material. It is ideal due to the fact that it is easily Obtainable given the extensive sugar cane cultivation making its supply constant and stable.

When appropriate modifications and manufacturing procedures are applied, Bagasse displays improved mechanical properties such as tensile strength, flexural strength, flexural modulus, hardness, and impact strength.

Bagasse is also found to be easily treated and modified with chemicals besides blending well with other materials to form new types of composite materials. It also satisfies the greening requirements by being biodegradable, recyclable and reusable 11 .

\subsection{Natural adhesive material}

Many of the proteins like gelatin, keratin, and casein consisting very interesting features of polymers such as flexural, shear strength, tensile modulus, as well as exceptional material properties including toughness, strength and elasticity. Thus, these proteins are also useful for the creation of new biodegradable polymer for various commercial applications 12, 14.

Protein-based biodegradable polymers they have an expanding range of potential applications in formation of food packaging, and as biomaterials like reconstructive surgery, tissue engineering.

In food packaging industries films made by protein polymers (like Milk proteins, Whey protein, Gelatin, Wheat gluten, Corn, Zein, Soy protein, Egg white, etc.) 9,10 .

The employment of protein concepts to edible packaging materials promises to improve barrier and mechanical properties and facilitate the effective incor- 
poration of bioactive ingredients and other functions such as tampering resistance 15 .

\section{Materials and methods}

\subsection{Fiber preparation}

Bagasse fiber (vegetable waste) was treated to use it in environmentally friendly packaging.

The fiber was treated by immersing it in a concentrated solution of sodium hydroxide in a concentration percentage (1 fiber: 10 sodium hydroxide) with boiling in the presence of an auxiliary agent (soap) for $90 \mathrm{~min}$.
After processing fibers, it washed thoroughly with hot water to remove the traces of the alkali used and stop the reaction process on the surface of the fibers, after completing the process of removing lignin from Bagasse fiber 2.

Fibers are then treated with a dilute solution of hydrochloric acid with concentrate $(0.4 \%)$ on cold condition, to treat the remaining alkyl in fibers, wash fibers with cold water, and let it to dry, table( 1) presented the properties of Bagasse fibers after treatment according to the standard test method for ASTM D3822/ D3822M 6-14.

Table (1): Bagasse Fibers Mechanical properties after treatment

\begin{tabular}{|c|c|c|c|c|}
\hline Properties & Fiber length & Fiber Diameter & Strength & Elongation \\
\hline Bagasse Fiber & $59 \mathrm{~mm}$ & $58 \underline{\underline{\text { micron }}}$ & $20 \mathrm{~g} / \mathrm{tex}$ & $5 \%$ \\
\hline
\end{tabular}

\subsection{Pre experimental}

After fiber preparation, the treated fibers was used to cover some kinds of vegetables and fruits at air atmosphere, mixed fibers( rind and pith of Bagasse fibers) was used without opining or any mechanical treatment, to see how it is useful to use these fiber as a packing material for fresh cut vegetables or fruits.

Covered three kinds of agriculture products with mixed Bagasse fibers, let it for approximately 10 days, then took photos for this experimental, as shown in figure( 1 ).

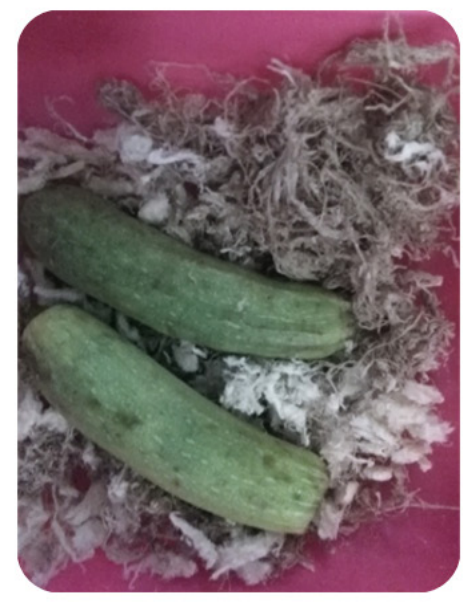

zucchini

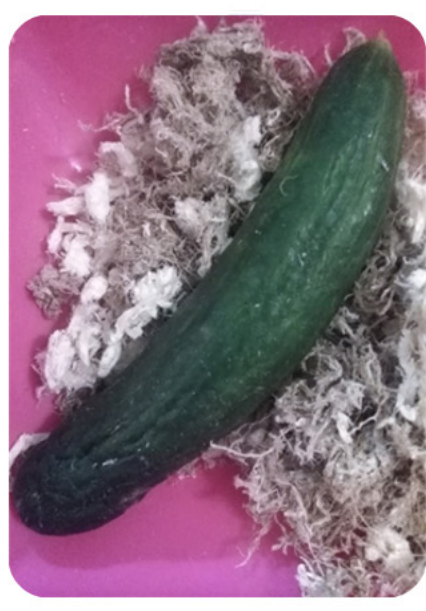

cucumber

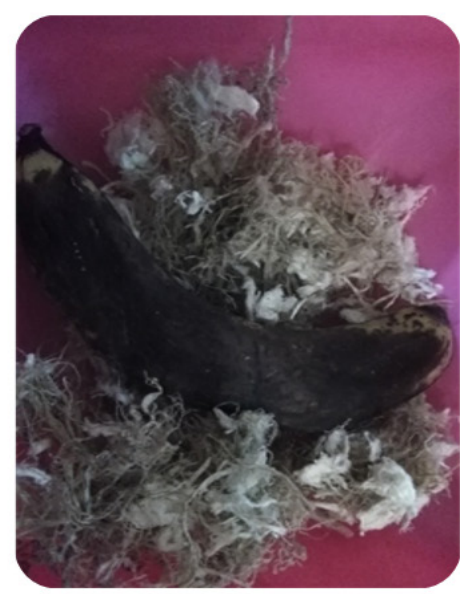

Banana

Figure (1): vegetables and fruits after 10 days 


\subsubsection{Main experimental}

After this experimental, treated fibers were opening by mechanical method, and convert the fibers to stable length, to be suitable for making nonwoven packing sheets.

Using natural adhesive material (natural gelatin powder).

Bagasse fibers were mixed with adhesive material, and compressed this mixture under pressure from 6 to
$10 \mathrm{MPa}$, and heated at $150^{\circ} \mathrm{C}$ to $170^{\circ} \mathrm{C}$, to stick fibers together, to have nonwoven Bagasse sheets.

Bagasse sheets, were consisted of mixed Bagasse fibers (from rind and pith of sugar cane Bagasse), and natural gelatin powder with percentage of (10 gm of mixed Bagasse fiber: $2 \mathrm{gm}$ of natural gelatin powder) to have a good adhesive sheet suitable to be use as a packing material.

Steps of preparing nonwoven Bagasse sheet were shown in figure (2).

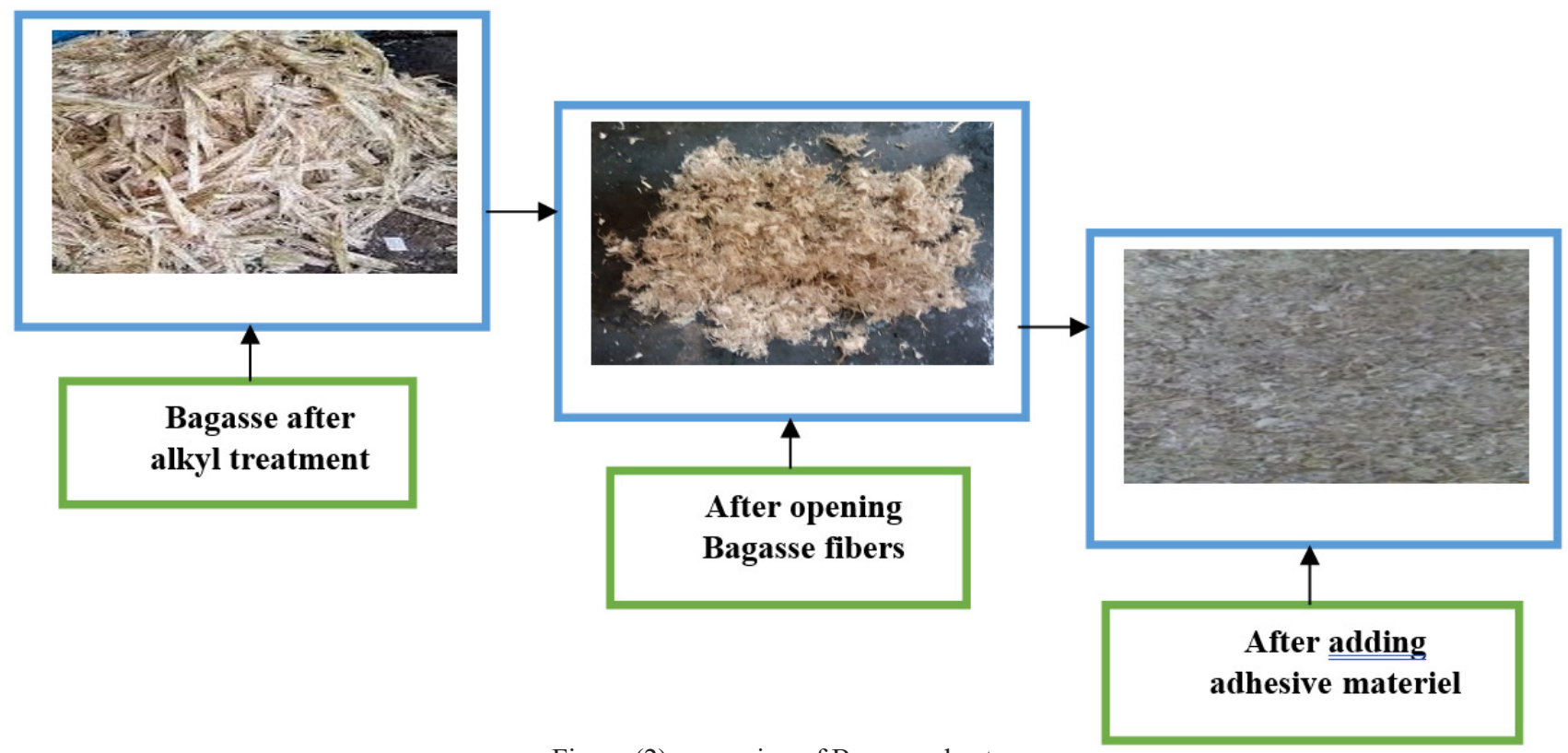

Figure (2): preparing of Bagasse sheet

\section{Results and Discussions}

In this paper we tested the influence of nonwoven packing products from bagasse fibers on shelf life of vegetables or fruits.

Three kinds of vegetables (Lemon, cucumber, zucchini) were tested, and measured the degradation of each of these specimens (covered with Bagasse sheets, and uncovered with Bagasse sheets), Bagasse sheet properties are shown at table (2).

Table (2): properties of Bagasse sheet

\begin{tabular}{|c|c|}
\hline Fiber length after opining & $1-2 \mathrm{~mm}$ \\
\hline Mixed ratio of Bagasse fibers & $50 \%$ from rind fibers: $50 \%$ from pith fibers \\
\hline Adhesive material & natural gelatin powder \\
\hline $\begin{array}{l}\text { Ratio between Bagasse fibers: } \\
\text { adhesive material }\end{array}$ & 10 gm of mixed Bagasse fiber: $2 \mathrm{gm}$ of natural gelatin powder \\
\hline
\end{tabular}

The experimental tests designed for 10 days to show how the degradation of the vegetables occur, and took photos for each period of experimental as shown in figure (3). 


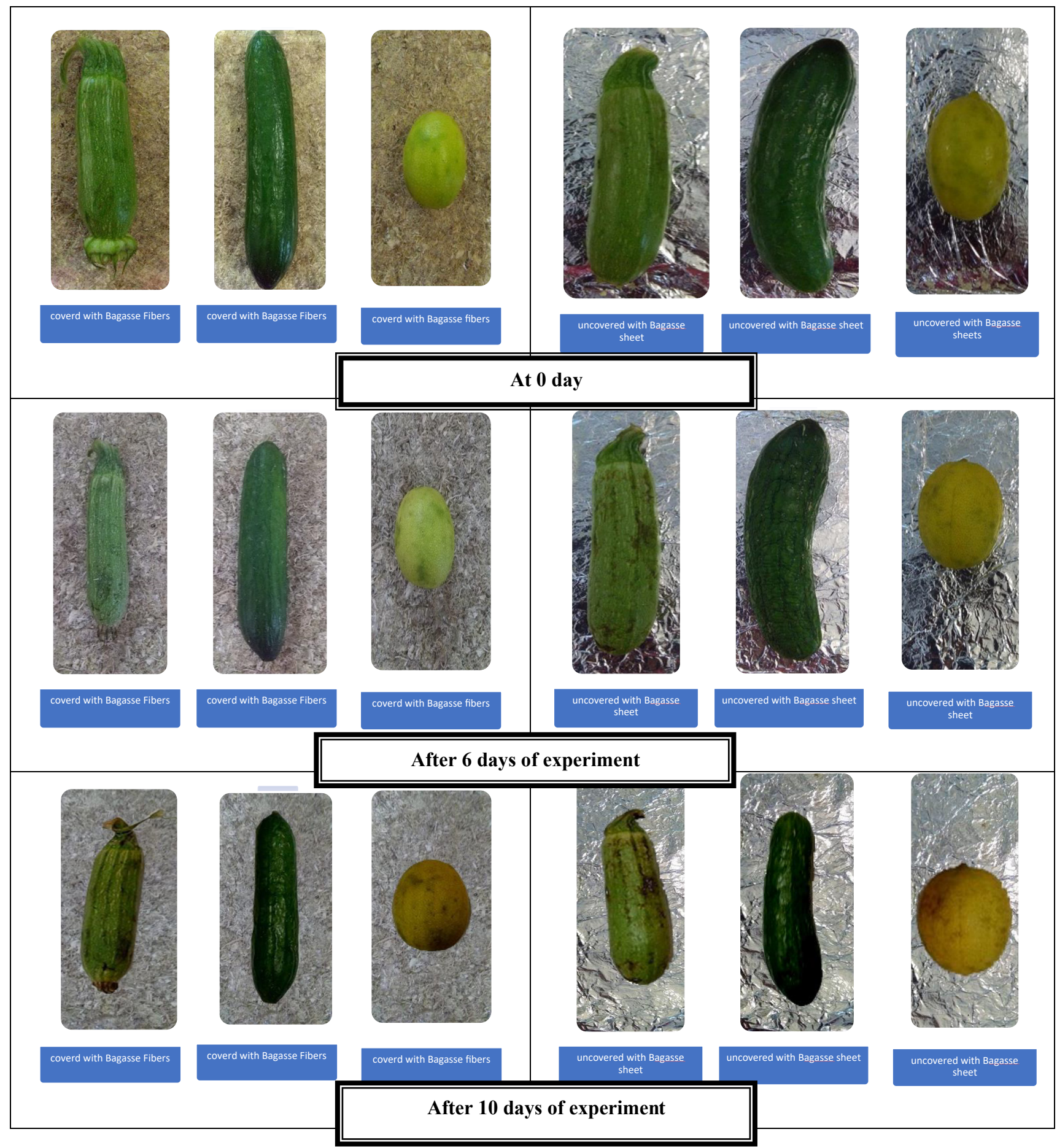

Figure (3): photos shows the degradable of specimens experiment 
The samples were tested in standard conditions for the air temperature which were $20 \pm 0.1 \mathrm{C} \mathrm{o}$, and humidity at $65 \pm 3 \%$ R.H.

Samples weight tested for the standard test method ASTM D3776 D3778M-09a, Texture profile analysis was determined according to Gomez et al., (2006), Physical evaluation of the products, Chemical composition for the standard test method A.O.A.C. (2000) 1,5,7 and 11.

Figure (3) shows samples photos which were tested in this research, and represented the degradation in each sample.

Weight, moisture contents and hardness of specimens are tested, at different times, table (3) represents the results of these tests.

Table (3): experimental tests results

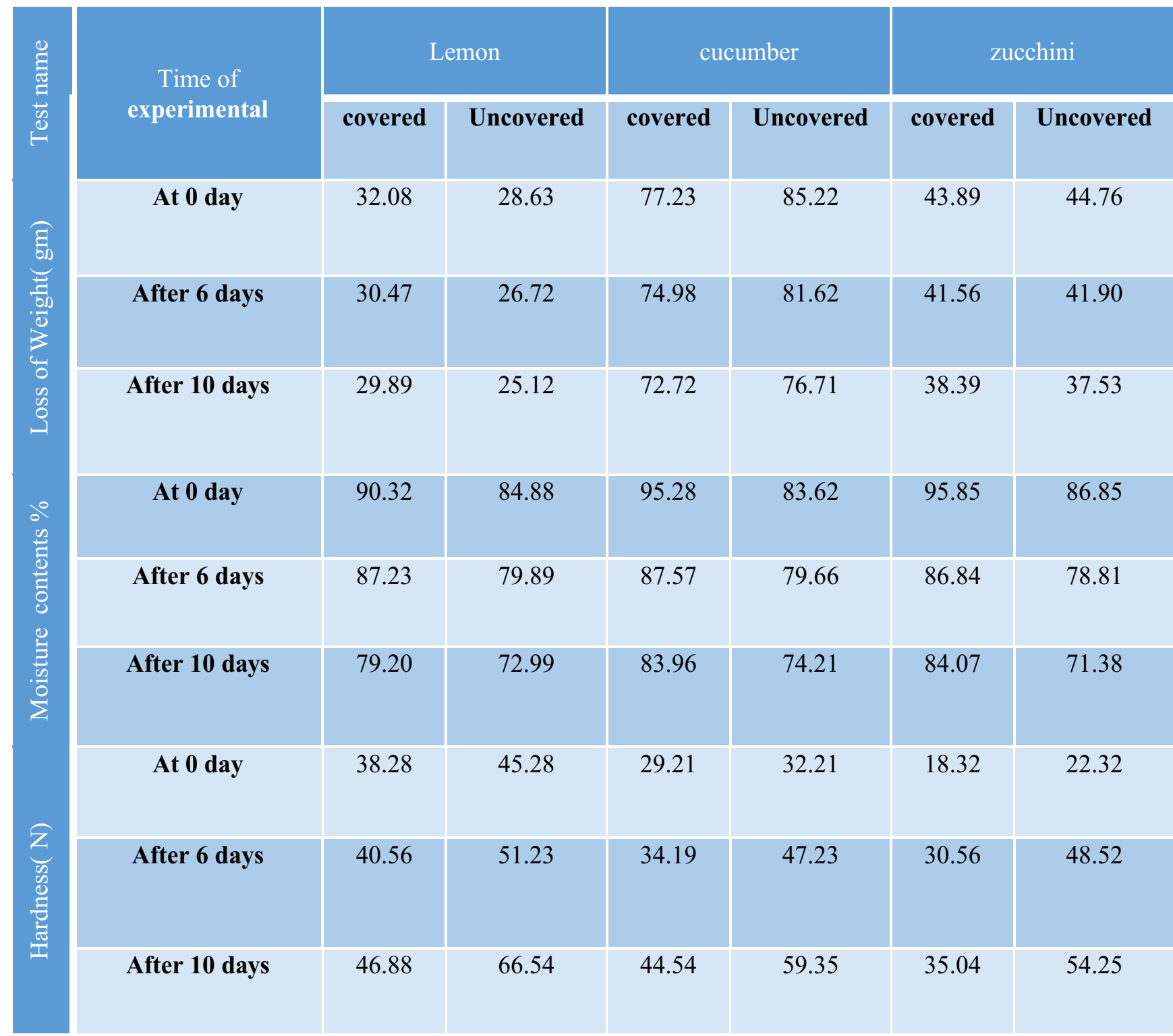

Figures 4, 5 and 6, showed the relation between each specimen in this experiment, for tests of loss of weight, hardness and moisture contents. 



Figure (4): Loss of specimens Weight (gm) 

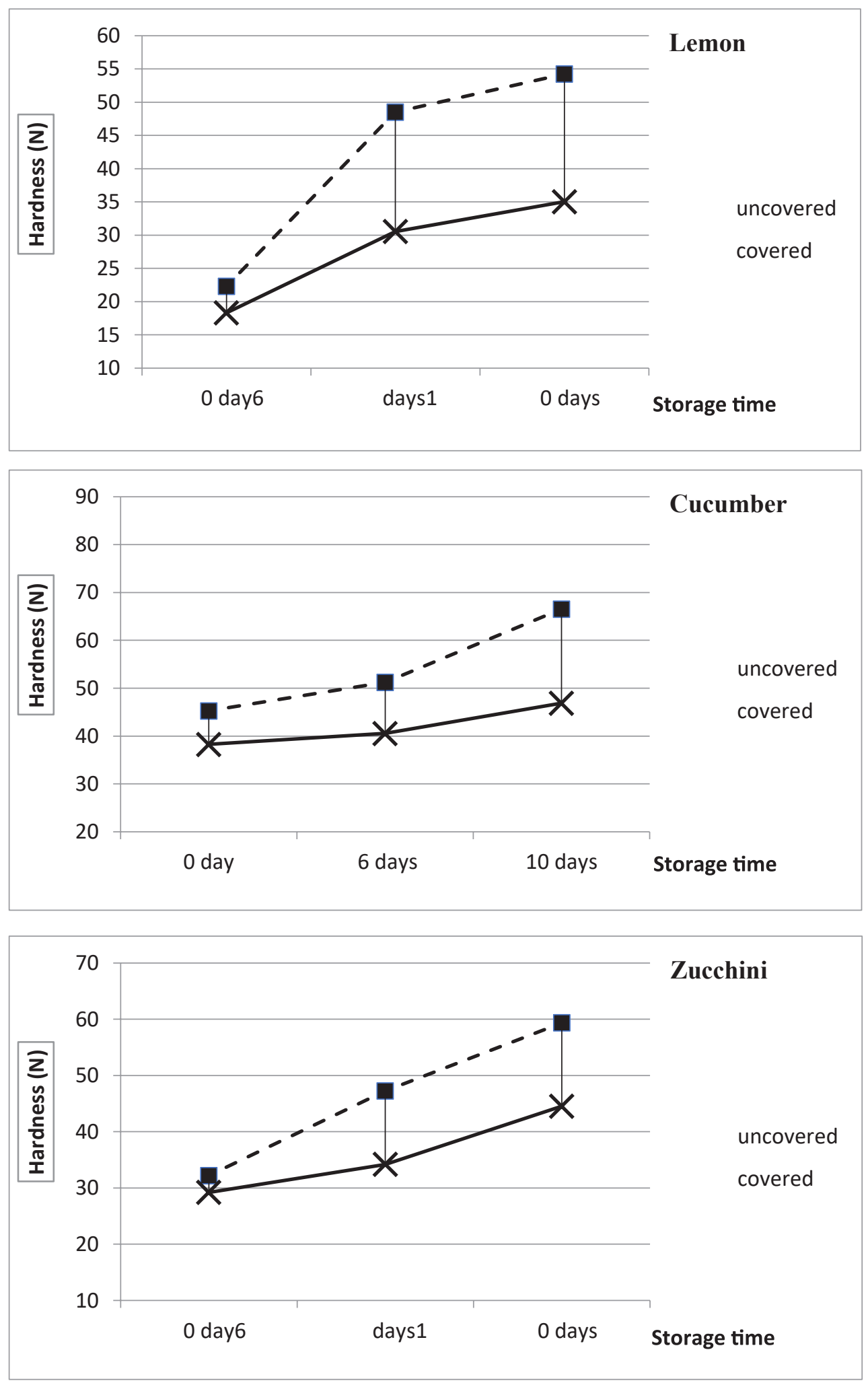

Figure (5): Hardness of specimens 

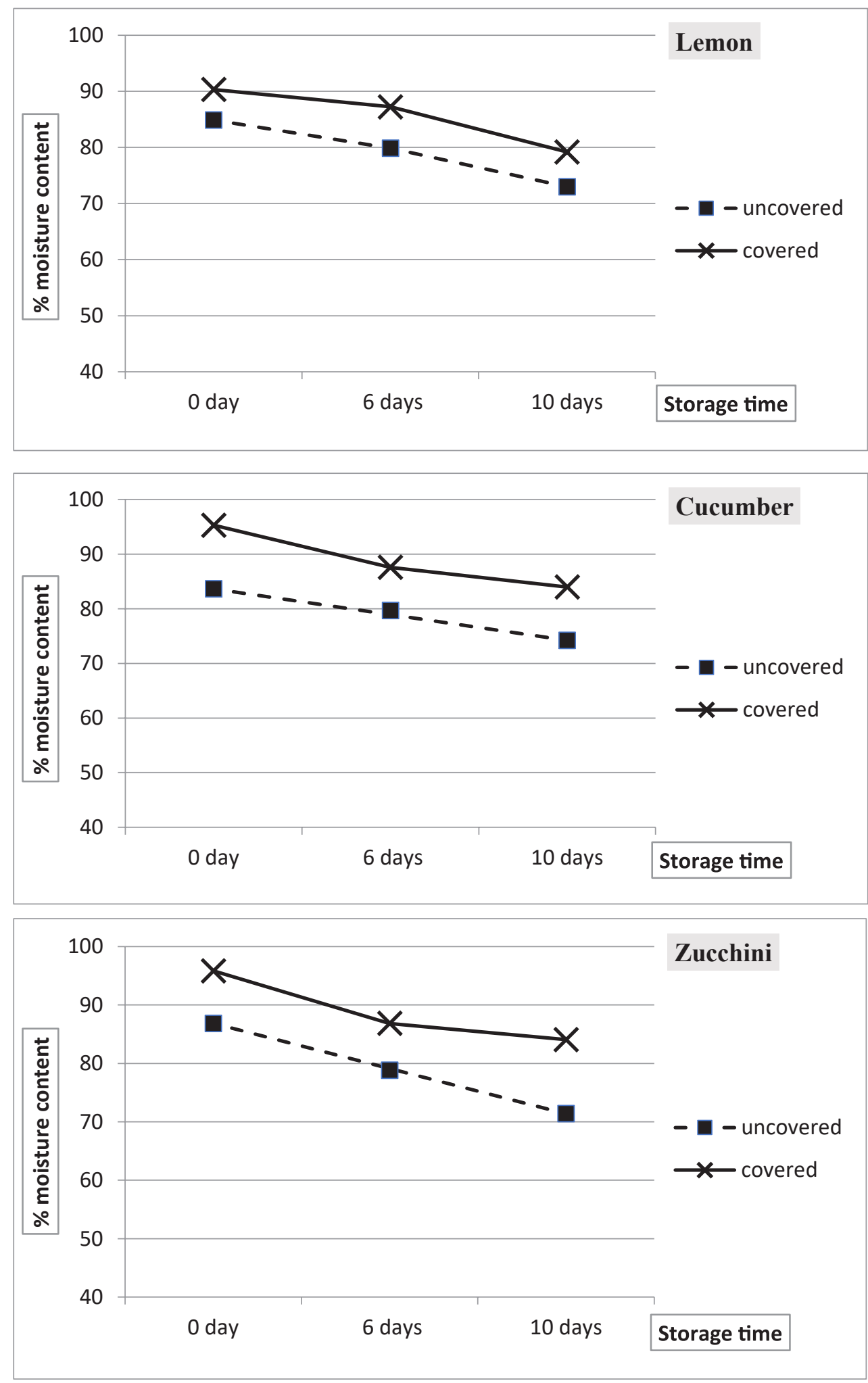

Figure (6): Moisture content $\%$ of specimens test 
Test of loss of weight (gm), for all specimens (Lemon, cucumber and zucchini), shows that, the loss of weight of specimens was less decrease when they covered with Bagasse sheet than other specimens that not covered with Bagasse sheet, as shown in figure (4), that means there is a significant difference in loss of weight (gm) between the specimens which covered with Bagasse sheet and the others which uncovered with Bagasse sheet in each specimen. Test of Hardness (N), for all specimens (Lemon, cucumber and zucchini), shows that, Hardness of specimens was less increase when they covered with Bagasse sheet than other specimens that not covered with Bagasse sheet, as shown in figure (5), that means there is a significant difference in increase of hardness between the specimens which covered with Bagasse sheet and the others which uncovered with Bagasse sheet in each specimen

Test of Moisture contents \%, for all specimens (Lemon, cucumber and zucchini), shows that, the loss of moisture contents of specimens was less decrease when they covered with Bagasse sheet than other specimens that not covered with Bagasse sheet, as shown in figure (6), that means there is a significant difference in loss of weight (gm) between the specimens which covered with Bagasse sheet and the others which uncovered with Bagasse sheet in each specimen

Hardness and moisture contents are reversing each other, it means that with increase in hardness, the moisture contents are decrease, and vice versa.

Both result of loose in specimen's weight and loose of moisture contents in uncovered specimens, caused to increase in specimen's hardness.

From the previous results, there is a significant difference between the specimens which covered with Bagasse sheet and the others which uncovered with Bagasse sheet.

- In loss of weight test, there is an increase of weighting loss for the uncovered specimens than the other at different times, the loss of weight refers to loss of moisture contents for uncovered specimens than other specimens which were covered with Bagasse sheet,

- There is less decrease in moisture content percentage for specimens which covered with Bagassse sheet than the uncovered specimens, which means hardness increased in the specimens which uncovered with nonwoven Bagasse sheet than the others.

Using of Bagasse sheets as a packing material save the loss of moisture contents in different specimens, which give more shelf life for these specimens.

\section{Conclusion:}

Using of nonwoven packing sheets from Bagasse fibers obtain longest shelf life for vegetables or fruits, and these packing apply to degradable naturally, without causing any more pollution for environment.

The efficiency of packing materials is influencing on vegetables shelf life, natural materials give more quality for specimens which packing in it, with degradable ability. Treated Bagasse fibers have good properties, such as fiber permeability and diffusivity, surface protection and exposed surfaces, especially its ability of absorption moisture, that safe vegetables or fruits from growth of bacteria or fungi. Nonwoven Bagasse sheets can be shaped to cups, plates or any other shape that suitable for fruits or vegetables shapes, which we need to keep.

\section{Reference:}

1. A.A.C.C. (1994): Approved method of the American Association of Cereal Chemist Published by American Association of Cereal Chemists Inc. st. paul, Minnesota, U.S.A, 1994.

2. Ahmed Salman, Azza Halwany (2011): The ability of Blended Plants Waste( Bagasse) in Manufacturing some types of Fabrics- Doctor of Philosophy- Faculty of Applied Arts- Hellwan University- Sep.2011.

3. Anuj K. Chandel,aSilvio S. da Silva and others (2012): Sugarcane Bagasse and leaves: Foreseeable Biomass of Biofuel and Bio-Products, J Chem Techno Biotechnology; Vol. 87, pp 11-20, 2012.

4. Anuj Kumar, Yuvraj Singh Negi, Veena Choudhary, Nishi Kant Bhardwaj (2014): Sugarcane Bagasse: A Promising Source for the Production of Nanocellulose, Journal of Polymer \& Composites, Vol. 2, Issue 3, pp 23-27, 2014.

5. A.O.A.C. (2000): Official Methods of the Association of Official Analytical Chemists 15th Ed., Published by the Association of Official Analytical Chemists. Arlington Virginia, U.S.A. 2000.

6. ASTM E96 (2007): Standard test methods for water vapor transmission of materials, 2007.

7. ASTM D3822/ D3822M-14(2014): Standard test method for single textile fibers, 2014.

8. Balaji1.A, Karthikeyan.B, and Raj.C.S. (2014): Bagasse Fiber-The Future Biocomposite Material, Int.J. ChemTech Res. Vol.7, No.01, pp 223-233, 2014.

9. Carvalho, Fernando E. Felissia, Maria C. Area. (2011): Composite Materials of Thermoplastic Starch and Fibers from the Ethanol-Water Fractionation of Bagasse Industrial Crops and Products, pp 739-746, 2011.

10. 10- Essam s. abd el-sayed*, Mohamed el-sakhawy and others (2019): eco-friendly mimosa tannin adhesive system for bagasse particleboard fabrication, egypt. j.chem., Vol. 62, No.5, pp 777- 787, 2019.

11. 11- Gomez, M., Ronda, F., Caballero, P. A., Blanco,c.A. and Rosell,C.M.(2006): Functionality of different hydrocolloids on the quality and shelf-life of yellow layer cakes Sci. Direct, pp 167173,2006 .

12. 12- Le Duy Khuong, Ryuichiro Kondo, Rizalinda De Leon, Bioethanol (2014): Production from alkaline-pretreated sugarcane bagasse by consolidated bioprocessing using Phlebia sp. MG-60, International Biodeterioration \& Biodegradation 88, pp 62 -68, 2014.

13. 13- Lois-Correa J.A. (2012): Depithers for Efficient Preparation of Sugar Cane Bagasse Fibers in Pulp and Paper Industry, Ingeniería Investigación y Tecnología, volumen XIII (número 4), December, pp 417-424, 2012.

14. 14- Riza Wirawan, SM Sapuan, Robiah Yunus, and Khalina Abdan (2012): Density and Water Absorption of Sugarcane Bagasse-Filled Poly(vinyl chloride) Composites, Polymers \& Polymer Composites, Vol. 20, No. 7,2012.

15. 15- S. Mangaraj, Ajay Yadav, Lalit M. Bal. and others (2018): application of biodegradable polymers in food packaging industry: a comprehensive review, journal of packaging technology and research November, 2018. 